\title{
Téoros
}

Revue de recherche en tourisme

\section{Le tourisme au Maroc}

\section{Entre le temps et les événements}

\section{Jean Stafford}

Volume 24, numéro 1, printemps 2005

Maroc, réalités et défis

URI : https://id.erudit.org/iderudit/1071111ar

DOI : https://doi.org/10.7202/1071111ar

Aller au sommaire du numéro

Éditeur(s)

Université du Québec à Montréal

ISSN

0712-8657 (imprimé)

1923-2705 (numérique)

Découvrir la revue

\section{Citer cet article}

Stafford, J. (2005). Le tourisme au Maroc : entre le temps et les événements.

Téoros, 24(1), 53-54. https://doi.org/10.7202/1071111ar

Ce document est protégé par la loi sur le droit d'auteur. L'utilisation des services d'Érudit (y compris la reproduction) est assujettie à sa politique d'utilisation que vous pouvez consulter en ligne.

https://apropos.erudit.org/fr/usagers/politique-dutilisation/
Cet article est diffusé et préservé par Érudit.

Érudit est un consortium interuniversitaire sans but lucratif composé de l'Université de Montréal, l'Université Laval et l'Université du Québec à Montréal. Il a pour mission la promotion et la valorisation de la recherche. https://www.erudit.org/fr/ 


\section{Le tourisme au Maroc Entre le temps et les événements}

\section{Jean Stafford}

L'industrie touristique au Maroc est un secteur économique important; bon an mal an, il représente de $8 \%$ à $10 \%$ du PIB du pays. Sur le plan touristique, le Maroc dispose d'atouts remarquables : son climat, sa culture spécifique, ses villes impériales et sa position géographique. Malgré ces avantages concurrentiels, le secteur du tourisme connait de profondes fluctuations dans les dernières années. Dans ce court article, nous allons analyser l'évolution récente du tourisme étranger de séjour, les nuitées dans la ville phare de Marrakech et les effets divergents des deux guerres du Golfe sur le tourisme marocain.

\section{Le tourisme au Maroc dans les quinze dernières années}

Le tableau 1 montre les taux d'accroissement annuel moyen ${ }^{1}$ pour "les touristes internationaux de séjour » par blocs de cinq années, de 1998 à 2002. La croissance des touristes, sur l'ensemble de la période, a été seulement de 0,8\%. De 1988 à 1992, la croissance annuelle a été remarquablement forte (avec 13,1\%). Cette période forte a été suivie d'un fléchissement très accentué dans les années 1993-1997 (une baisse annuelle de -11,3\%). Enfin, la période plus récente, de 1998 à 2002, connaît une croissance modeste de 2,6\% annuellement. Ces données montrent que l'industrie touristique marocaine est durement touchée par des cycles de courtes périodes qui nuisent grandement à son développement. Ces cycles dépendent, à la fois, de facteurs politiques et économiques; comme le signale Mimoun Hillali : "Le tourisme, secteur vital pour le Maroc et la Tunisie, ne s'est pas remis des conséquences d'une décennie de chocs économiques et de conflits militaires qui ont secoué (et continuent d'ailleurs de le faire) les pays arabes, en particulier, et le monde en général. » (Hillali, 2004 : 38)
Tableau 1

\begin{tabular}{|c|c|}
\hline \multicolumn{2}{|c|}{$\begin{array}{l}\text { Les taux d’accroissement annuel moyen } \\
\text { (moyenne géométrique) } \\
\text { des « touristes internationaux de séjour » } \\
\text { au Maroc, par blocs de cinq années, } \\
\text { de } 1988 \text { à } 2002\end{array}$} \\
\hline Années & Taux d'accroissement annuel moyen \\
\hline 1988-1992 & $13,1 \%$ \\
\hline 1993-1997 & $-11,3 \%$ \\
\hline 1998-2002 & $2,65 \%$ \\
\hline 1988-2002 & $0,8 \%$ \\
\hline
\end{tabular}

Source : Nos calculs à partir des données du ministère du Tourisme, Royaume du Maroc.

\section{Les nuitées à Marrakech}

Marrakech est le plus beau fleuron des villes impériales marocaines ; à elle seule, Marrakech compte pour le tiers des nuitées de l'ensemble du pays; elle est un microcosme qui permet d'analyser la situation du tourisme. Cinq pays européens constituent les principales clientèles du tourisme, à la fois pour " les touristes internationaux de séjour " et pour les nuitées à l'hôtel. Ces cinq pays, la France, l'Espagne, l'Angleterre, l'Allemagne et l'Italie, représentent $68 \%$ de l'ensemble des clientèles touristiques étrangères.

Le tableau 2 présente les taux d'accroissement annuel moyen des nuitées à Marrakech pour ces cinq pays, pour la période 1999-2003. La croissance des nuitées des touristes français est faible (1 \% par année) ; on constate une baisse très forte des nuitées des touristes espagnols (-18,2\%), allemands $(-27,5 \%)$ et italiens $(-16,9 \%)$; seuls les touristes anglais représentent une clientèle en véritable croissance $(7,6 \%)$.

Les parts de marché ${ }^{2}$ de ces diverses clientèles ont beaucoup évolué dans les dix dernières années : en 1993, les touristes français représentaient $59 \%$ des nuitées ; ce pourcentage est passé à 73 \% en 1999 et à $83 \%$ en 2003. Marrakech, ce joyau du Royaume, est devenu une véritable attraction touristique pour les élites françaises des mass média, du monde du spectacle et même des ténors de la politique. L'industrie du tourisme à Marrakech est de plus en plus dépendante de la venue des touristes français.

\section{Tableau 2}

\begin{tabular}{l|c}
$\begin{array}{c}\text { Les taux d'accroissement annuel moyen } \\
\text { (moyenne géométrique) }\end{array}$ \\
des nuitées à Marrakech, de 1999 à 2003 \\
\hline Pays & Taux d'accroissement annuel moyen \\
\hline France & $1 \%$ \\
Espagne & $-18,2 \%$ \\
Angleterre & $7,6 \%$ \\
Allemagne & $-27,5 \%$ \\
Italie & $-16,9 \%$
\end{tabular}

Source: Nos calculs à partir des données du ministère du Tourisme, Royaume du Maroc.

\section{Les effets des deux guerres du Golfe}

Dans cette partie, nous allons traiter des effets sur le tourisme marocain des deux guerres du Golfe.

\section{Les effets sur "les touristes internationaux de séjour"}

Le tableau 3 présente les taux d'accroissement annuel moyen pour la période $1991 / 1990^{3}$ et les taux d'accroissement annuel moyen pour la période 2003/2002 ${ }^{4}$. Nous pouvons constater que, pour certains pays, les comportements touristiques diffèrent de façon importante entre les deux périodes de guerre. Lors de la première guerre du Golfe, en 1991, la baisse des arrivées des touristes a été très forte dans tous les pays étudiés. En 2003, la situation est bien différente : les arrivées des touristes français augmentent de $3,1 \%$, celles des touristes espagnols de 11,2\% ; la baisse des entrées des touristes anglais est beaucoup plus faible en 2003, par contre la décroissance des arrivées des touristes allemands et italiens reste assez importante lors de la deuxième guerre du Golfe. 


\section{Les effets sur les nuitées à Marrakech}

Nous constatons à Marrakech (voir le tableau 4) une baisse moins dramatique des nuitées en 2003 (par rapport à 1991); dans le cas de la France, la décroissance est nulle alors qu'elle était de -60 \% en 1991 ; chez les touristes anglais, il y a même une croissance des nuitées de 2,2\%. Les nuitées des touristes espagnols connaissent une baisse de 10,4\% en 2003 (la baisse était de -21,1 \% en 1991). Chez les touristes en provenance de

\section{Tableau 3}

Les taux d'accroissement annuel moyen (moyenne géométrique) des

" touristes internationaux de séjour " au Maroc, pour les périodes 1991/1990 et 2003/2002

\begin{tabular}{lc|c} 
Pays & $\begin{array}{c}\text { Taux d'accroissement } \\
\text { annuel moyen } \\
\boldsymbol{1}^{\mathrm{e}} \text { guerre du Golfe } \\
\text { (Koweit) 1991/1990 }\end{array}$ & $\begin{array}{c}\text { Taux d'accroissement } \\
\text { annuel moyen } \\
\mathbf{2}^{\mathrm{e}} \text { guerre du Golfe } \\
\text { (Iraq) 2003/2002 }\end{array}$ \\
\hline France & $-35,7 \%$ & $3,1 \%$ \\
Espagne & $-8,3 \%$ & $11,2 \%$ \\
Angleterre & $-34,6 \%$ & $-4,8 \%$ \\
Allemagne & $-32,7 \%$ & $-26,8 \%$ \\
Italie & $-16 \%$ & $-13,1 \%$
\end{tabular}

Source : Nos calculs à partir des données du ministère $d u$ Tourisme, Royaume du Maroc.
l'Allemagne et de l'Italie, la décroissance des nuitées à Marrakech en 2003 reste assez forte.

\section{Les leçons du passé}

L'industrie touristique marocaine est touchée par de fortes fluctuations; ces fluctuations sont provoquées par des causes internes et externes : la faible rentabilité et les problèmes de financement dans le secteur de l'hôtellerie, les contraintes exercées par la concurrence inter-

\section{Tableau 4}

Les taux d'accroissement annuel moyen (moyenne géométrique) des nuitées à Marrakech,

pour les périodes 1991/1990 et 2003/2002

Pays

\begin{tabular}{|c|c|}
\hline $\begin{array}{c}\text { Taux d'accroissement } \\
\text { annuel moyen } \\
1^{e} \text { guerre du Golfe } \\
\text { (Koweit) 1991/1990 }\end{array}$ & $\begin{array}{l}\text { Taux d'accroissement } \\
\text { annuel moyen } \\
2^{\mathrm{e}} \text { guerre du Golfe } \\
\text { (Iraq) } 2003 / 2002\end{array}$ \\
\hline$-60,5 \%$ & $0,0 \%$ \\
\hline$-21,1 \%$ & $-10,4 \%$ \\
\hline$-65,6 \%$ & $2,2 \%$ \\
\hline$-47,1 \%$ & $-39,7 \%$ \\
\hline$-32,2 \%$ & $-21,4 \%$ \\
\hline
\end{tabular}

Italie

$-32,2 \%$

$-21,4 \%$

Source: Nos calculs à partir des données du ministère $d u$ Tourisme, Royaume du Maroc. nationale, les troubles économiques et politiques mondiaux. II faut aussi souligner la forte dépendance du tourisme marocain vis-à-vis cinq grands pays européens. Enfin, une bonne nouvelle, il semble y avoir une certaine atténuation du risque politique associé à la destination marocaine pour les touristes français, anglais et espagnols; les touristes en provenance de l'Allemagne et de l'Italie demeurent sensibles face à ce phénomène.

Jean Stafford est économiste et professeur au Département d'études urbaines et touristiques de l'Université du Québec à Montréal.

\section{Notes}

1 II s'agit du taux d'accroissement annuel moyen calculé avec une moyenne géométrique.

2 Nous rappelons que le total des nuitées est formé des cinq principaux pays nommés plus haut.

3 La première guerre du Golfe - la guerre du Koweit - a été déclenchée le 16 janvier 1991.

4 La deuxième guerre du Golfe - la guerre en Iraq - a été déclenchée le 20 mars 2003.

\section{Bibliographie}

Hillali, Mimoun (2004), «Risque politique et tourisme au Maghreb », Téoros, vol. 23, n 1, p.38.

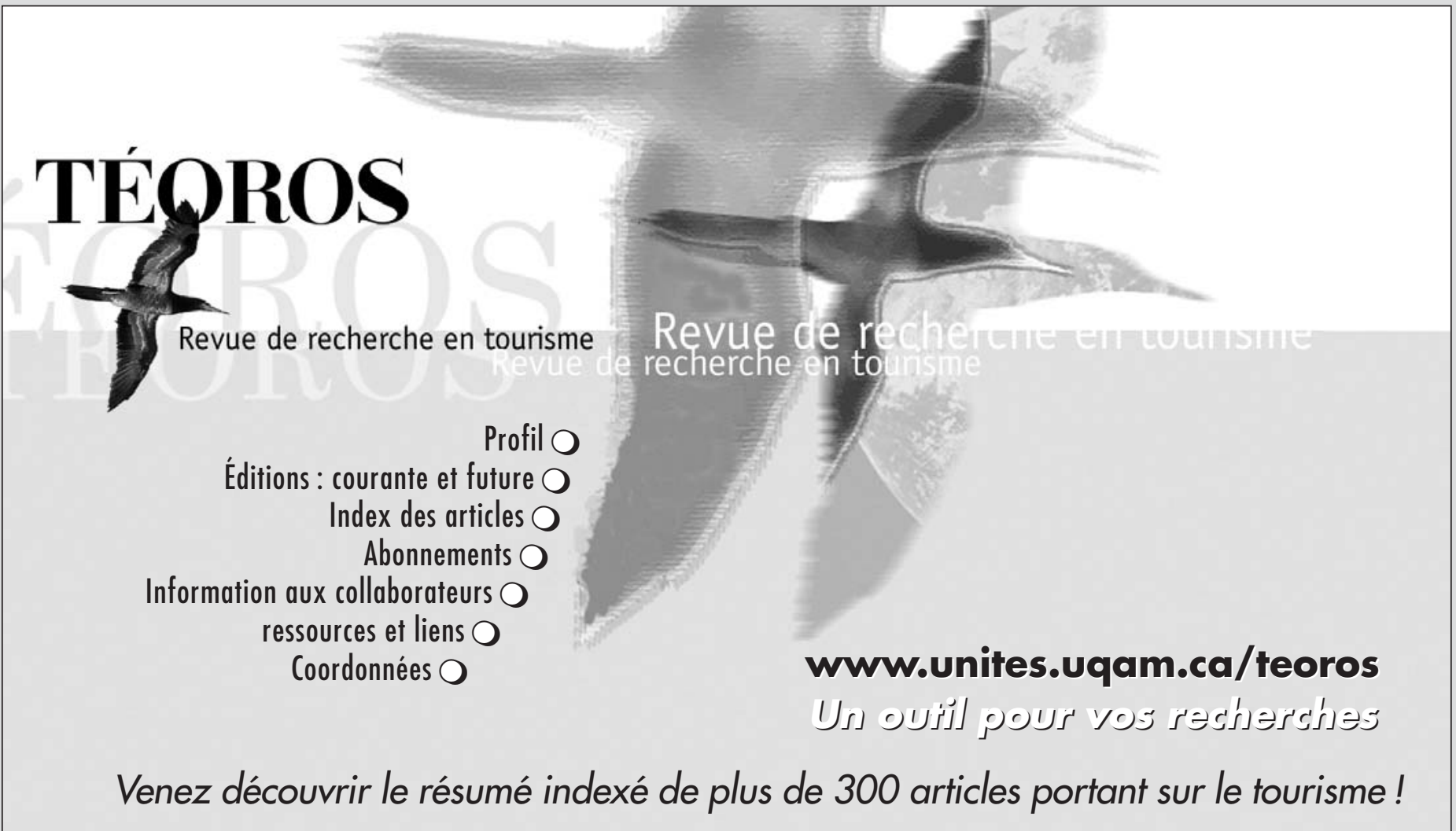

